\title{
INITIATION OF CaSO 4 SCALE FORMATION ON HEAT TRANSFER SURFACES UNDER POOL BOILING CONDITIONS
}

\author{
M.R. Malayeri and H. Müller-Steinhagen
}

Institute of Thermodynamics and Thermal Engineering, University of Stuttgart, Pfaffenwaldring 6, D-70550,

Stuttgart, Germany, m.malayeri@itw.uni-stuttgart.de

German Aerospace Research Centre (DLR), Pfaffenwaldring 38-40, D-70569, Germany, Hans.Mueller-Steinhagen@dlr.de

\begin{abstract}
The success of innovative fouling mitigation techniques such as ion implantation depends upon early stage of scale formation on heat transfer surface. This is because the first crystalline nuclei that appear on the surface during the initial period dictate how fouling would develop in latter stages. In this study, the initial period of deposition of calcium sulphate on heat transfer surfaces has been investigated under pool boiling conditions. The independent variables were heat flux and calcium sulphate concentration. The experimental results show that the time until the heat transfer coefficient reaches its intermediate maximum decreases with increasing concentration and heat flux, and is also significantly affected by the surface finish. Neural network architectures were utilized to correlate the experimental results during the initial deposition period. A satisfactory agreement between predicted and measured heat transfer coefficients has been achieved with an average error of $8.7 \%$.
\end{abstract}

\section{INTRODUCTION}

Boiling heat transfer is one of the most efficient means of energy transfer per heat transfer unit area in thermal processes, due to:

- high surface temperature above saturation;

- bubble behaviour resulting in agitation of the thermal boundary layer.

However, the formation of deposit layers on heat transfer surfaces may severely reduce the efficiency of heat exchangers, in particular during pool boiling. The deposition of unwanted materials with low thermal conductivity causes heat transfer coefficients to drop considerably, leading to additional energy requirements to maintain the desired process conditions on target. In many cases, ultimately, operations have to be stopped for cleaning.

Such conditions arise in many heat exchangers in which nucleate boiling is the dominant process, perhaps kettle reboilers and steam generators provide the most spectacular examples. Fouling of heat exchangers with pool boiling is more severe and hence more complicated than with forced convective heat transfer. This is mainly due to higher surface temperatures, bubble behaviour, and rapid supersaturation of salts with inverse solubility beneath bubbles, which all play a key role in the process of scale formation.

In this investigation, the initial period of fouling during pool boiling heat transfer has been investigated. Published experimental results for this region are scarce, and most previous investigations have dealt with the full process of scale formation without paying detailed attention to the initial period. Nevertheless, this topic is of particular importance because:

- The first crystalline nuclei that appear on the surfaces during the initial period are decisive for analysing and understanding of the fouling mechanism.

- During the initial period, bubbles are in direct contact with the heat transfer surfaces, while they are subsequently in contact with the scale layer. Therefore, the success of novel fouling prevention techniques, such as surface coating by ion implantation or sputtering, is highly depended on the initial surface conditions (such as surface tension, surface energy and roughness) and the initial period of scale formation.

This paper starts with a brief review of previous studies of this topic. It will then address the influence of different operating parameters such as heat flux and salt concentration on scale initiation and formation during boiling. Finally, the experimental results will be correlated using artificial neural networks. The resulting network estimates the initial fouling behaviour with good accuracy. It could ultimately be coupled with the recent model by Jamialahmadi and Müller-Steinhagen (2004) that predicts the deposition rate beyond the initial period of scale formation during pool boiling heat transfer.

\section{BACKGROUND}

There have been few serious attempts to understand the effect of boiling mechanisms on the formation of scale under pool boiling conditions. These studies are generally divided into two distinct but interrelated categories namely single tubes and tube bundles. For single tubes, Partridge and White (1929); Freeborn and Lewis (1962); Hospeti and Mesler (1965); Palen and Westwater (1966); Jamialahmadi et al. (1989, 1993 and 2004) and Bornhorst et al. (1999) are among the investigators who have offered explanations for the mechanisms of fouling. For tube bundles the 
experimental results are sparse and non-conclusive (Malayeri et al., 2005). In the present study, the focus is, therefore, only on the initial period for fouling on single tubes.

Jamialahmadi and Müller-Steinhagen (1993), in a review paper on fouling during boiling, reported that the primary causes of fouling for solutions with inverse solubility are supersaturation and bubble formation behaviour. They also stated that the following steps take place when a deposit layer forms on the surface of a single tube during pool boiling:

- Bubble nuclei form just above the nucleation sites that are available on the surface. The bubble density is directly proportional to the number of nucleation sites, and hence the surface material and roughness are of prime importance.

- Bubble agitation initially produces considerable turbulence that enhances heat transfer. In this phase, bubble characteristics such as size, shape and rise velocity are affected by the physical/chemical properties of the boiling liquid, notably surface tension.

- Beneath the bubbles, a microlayer exists, in which the concentration of the dissolved salt is increased due to the preferential evaporation of the solvent. If the dissolved salt has an inverse solubility relationship with temperature, the considerable temperature gradient in the microlayer leads to further supersaturation of the solution. Under such circumstances, crystal nuclei will begin to precipitate on the surface and a deposit layer builds up, initially in the form of concentric rings around the nucleation sites. Both, surface temperature and bulk concentration dominate the formation and thickness of the fouling layer in this phase.

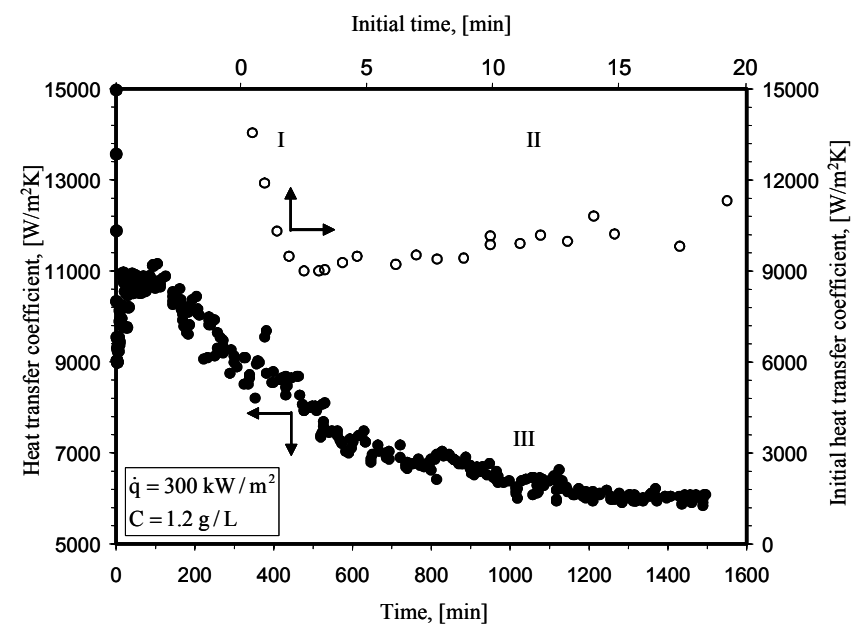

Figure 1. Typical variation of heat transfer coefficient as a function of time (Malayeri et al, 2005). In this figure, solid and open symbols correspond to complete run and initial period of $20 \mathrm{~min}$, respectively.
Fig. 1 illustrates typically how heat transfer coefficient varies as a function of time for a concentration of $1.2 \mathrm{~g} / \mathrm{L}$ and a heat flux of $300 \mathrm{~kW} / \mathrm{m}^{2}$ (Malayeri et al., 2005). Open circles correspond to data for the initial period up to $20 \mathrm{~min}$, which are difficult to recognize in the complete experimental run which is shown as solid circles. As it can be seen the heat transfer coefficient drops rapidly [region I] followed by a gradual recovery to an intermediate maximum [region II] which in turn is followed by a more gradual decline towards an asymptotic value of about 6000 $\mathrm{W} / \mathrm{m}^{2} \mathrm{~K}$ [region III]. Firstly, unlike forced convective heat transfer, one cannot see any induction period of non-fouling behaviour of zero fouling resistance. This could be due to rapid increase in concentration of salt in the micro-layer beneath the growing bubbles. Secondly, most and upright changes occur in regions I and II (called initial period hereafter) in which significant changes in heat transfer coefficient happens. Jamialahmadi and Müller-Steinhagen (2004) showed that in region I, the number of nucleation sites remains almost constant and bubbles are rather reluctant to detach due to surface tension. This together with rapid supersaturation of solution beneath bubbles would give rise to initial reduction of heat transfer coefficients. In region II, however, the number of nucleation sites (known as secondary nucleation sites) increases due to formation of first deposit nuclei that would then result in a higher number of generated bubbles and consequently higher heat transfer coefficients. Finally in region III, surface temperature and hence bubble generation declines due to the development of fouling layer which in turn gives rise in more moderate decrease in heat transfer coefficient. Nonetheless the initial period, in which also the first crystalline nuclei appear on the surface, is decisive for analysing and understanding of the fouling mechanism.

\section{EXPERIMENTAL SET-UP AND PROCEDURE}

The preliminary experimental results which will be analysed in this study were carried out by Bartlett (1995) as part of his MSc thesis (University of Auckland, New Zealand) and thus more details of the test rig and analysis of the errors are referred to this thesis. However a brief description of the experimentation is as follows.

Fig. 2 depicts a schematic diagram of the experimental equipment. The test rig has been used to measure heat transfer coefficient under pool boiling conditions for various concentrations and heat fluxes. The fully integrated experimental rig consists of a boiling vessel with a resistance band heater [1], an enclosed flow loop including a co-current condenser [2], a preheater [3], rod heater with power control units [4] and a data acquisition system [5] connected to a computer [6].

The rod heater is mounted horizontally in the centre of vessel and is manufactured by Ashland Chemical Company 
to an HTRI design. Four type $\mathrm{E}$ thermocouples are embedded inside the heater to measure the wall temperature. The heated zone is $99.1 \mathrm{~mm}$ long and the heat flux of the test heater can be varied up to $300 \mathrm{~kW} / \mathrm{m}^{2}$. Three of the embedded thermocouples are used for data acquisition and the fourth is used as a trip input for the test heater Variac power supply, should the internal temperature of the heater exceed a set limit.

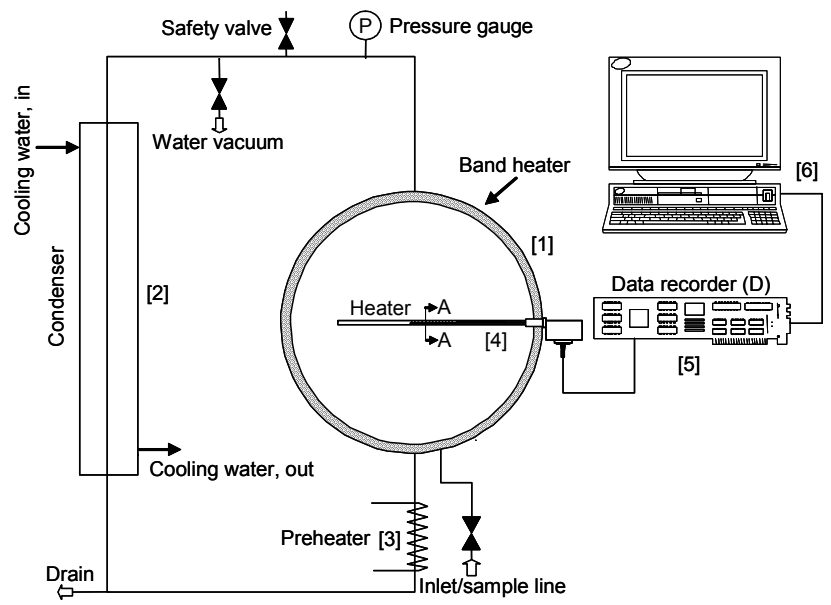

Figure 2. Schematic representation of test rig. using:

The average heat transfer coefficient is determined

$\alpha=\frac{\dot{q}}{\left(T_{s}-T_{b}\right)}$

and the fouling resistance due to deposition of a fouling layer is then calculated as a function of time from:

$$
R_{f}=\left(\frac{T_{s}-T_{b}}{\dot{q}}\right)_{t}-\left(\frac{T_{s}-T_{b}}{\dot{q}}\right)_{0}
$$

In this equation, $T_{\mathrm{s}}$ and $\mathrm{T}_{\mathrm{b}}$ are surface and bulk temperatures, respectively. The subscripts " $\mathrm{t}$ " and " 0 " denote conditions at any time and at the beginning of the experiment when the heat exchanger is considered to be clean, respectively.

Test solutions of calcium sulphate were prepared by dissolving calcium sulphate hemi-hydrate $\left(\mathrm{CaSO}_{4} \cdot \frac{1}{2} \mathrm{H}_{2} \mathrm{O}\right)$ in a separate container. The saturation concentration of $\mathrm{CaSO}_{4} \cdot 1 / 2 \mathrm{H}_{2} \mathrm{O}$ at $100^{\circ} \mathrm{C}$ is $1.6 \mathrm{~g} / \mathrm{L}$. The range of operating parameters used in this investigation is given in Table 1 along with corresponding surface temperatures for each heat flux.

Table 1. Range of operating parameters.

\begin{tabular}{|c|c|c|c|c|}
\hline & \multicolumn{3}{|c|}{$\mathrm{CaSO}_{4}$ Concentration, [ $\left.\mathrm{g} / \mathrm{L}\right]$} \\
\hline & & 1.6 & 1.2 & 0.8 \\
\hline \multirow{6}{*}{ 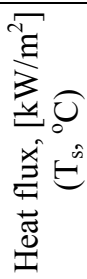 } & $55\left(104.3^{\circ} \mathrm{C}\right)$ & + & & \\
\hline & $76\left(106.6^{\circ} \mathrm{C}\right)$ & + & & \\
\hline & $105\left(107.4^{\circ} \mathrm{C}\right)$ & + & + & \\
\hline & $145\left(109.2^{\circ} \mathrm{C}\right)$ & + & + & + \\
\hline & $200\left(110.5^{\circ} \mathrm{C}\right)$ & + & + & \\
\hline & $300\left(114.1^{\circ} \mathrm{C}\right)$ & + & + & + \\
\hline
\end{tabular}

\section{RESULTS AND DISCUSSION}

\section{Effect of heat flux}

The variation of heat transfer coefficient during the initial period for different heat fluxes and a constant salt concentration of $1.6 \mathrm{~g} / \mathrm{L}$ is illustrated in Fig. 3. All five data sets exhibit the same trend as already shown in Fig. 1, i.e. a rapid decrease in heat transfer coefficient, followed by a recovery to a plateau. Apparently in the initial period, heat transfer coefficients depend strongly on the heat flux. However Malayeri et al. (2005) showed in the decay period in which heat transfer coefficient reaches its asymptotic value, this dependency on heat flux declines. For the initial period, it can thus be hypothesised that:

1. The difference between minimum heat transfer coefficient (end of region I) and clean value (zero time) widens as heat flux increases.

2. The time in which the heat transfer coefficient reaches the minimum value decreases with increasing heat flux as shown by the solid line in Fig. 3. For instance, for 76 $\mathrm{kW} / \mathrm{m}^{2}$, it is about $27 \mathrm{~min}$, while it is only about $1-2 \mathrm{~min}$ for $300 \mathrm{~kW} / \mathrm{m}^{2}$. This trend is consistent with observations by Palen and Westwater (1966) and Jamialahmadi et al. (1989). The effect of heat flux may be explained by analysing the mechanisms of bubble nucleation.

The increase of heat flux may lead to firstly the activation of smaller nucleation sites and secondly break up of generated bubbles. Nucleate pool boiling can only occur when the heated surface contains very small pits and cracks known as "cavities", that are required for bubble nucleation. A cavity can ideally be imagined as being conical and having a circular opening. For non-fouling pool boiling on clean metal surfaces, Whalley (1996) proposed the following equation for the prediction of the cavity radius:

$$
R=\frac{2 \sigma T_{\text {sat }}}{\rho_{g} \Delta h_{v} \Delta T_{\text {superheat }}}
$$


In this equation, $R$ is the cavity radius, $\sigma$ the surface tension, $\rho_{\mathrm{g}}$ the density of the vapour and $\Delta \mathrm{h}_{\mathrm{v}}$ the latent heat of evaporation. The equation indicates that as the wall superheat increases, more cavities of smaller radius are able to become active, giving rise to a higher heat transfer rate. The same mechanism applies at the start of the fouling process when both, degree of wall superheat and number of nucleation sites, dominate the development of the additional thermal resistance.

The second impact of heat flux is the break-up of big bubbles into much more smaller bubbles. At high heat fluxes (here $300 \mathrm{~kW} / \mathrm{m}^{2}$ which, at $1 \mathrm{bar}$, corresponds to a surface temperature of $114.1^{\circ} \mathrm{C}$ ) bubble break-up occurs, giving rise to small and almost undistinguishable individual rigid bubbles. Formation of these small bubbles and their subsequent release into the surrounding liquid enhances convection currents around the heater and as a result the heat transfer coefficient increases.

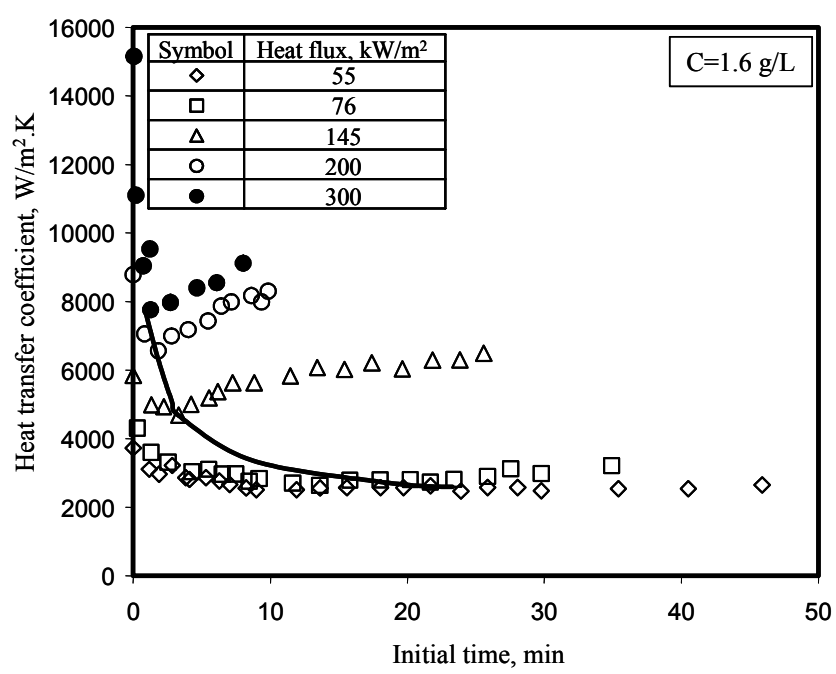

Figure 3. Variation of heat transfer coefficient for a given concentration and different heat fluxes in the initial period (region I and II in Fig. 1).

\section{Effect of $\mathrm{CaSO}_{4}$ Concentration}

An analysis of $\mathrm{CaSO}_{4}$ concentration effects under clean conditions would primarily shed light into heat transfer mechanisms as well as fouling mechanisms. Najibi et al. (1996) investigated the effect of $\mathrm{CaSO}_{4}$ concentration on boiling heat transfer from clean surfaces. They observed a relatively uniform bubble diameter of around $2 \mathrm{~mm}$ and a low bubble departure frequency during saturated pool boiling of distilled water for low heat fluxes $\left(38 \mathrm{~kW} / \mathrm{m}^{2}\right.$ which corresponds to a surface temperature of $103.7^{\circ} \mathrm{C}$ at 1 bar). As the concentration of salts with inverse solubility (such as $\mathrm{CaSO}_{4}$ ) was increased from 0.253 to $1.5 \mathrm{~g} / \mathrm{L}$, the number of active bubble nucleation sites decreased and the bubble departure diameter increased from $2.1 \mathrm{~mm}$ to 3.2 $\mathrm{mm}$. Therefore, the increasing $\mathrm{CaSO}_{4}$ concentration results in lower heat transfer coefficients due to changes in the mechanisms of bubble formation associated with the changing physical properties of the solution, particularly surface tension.

Fig. 4 illustrates the deposition-related changes in heat transfer coefficient as a function time for various concentrations, at a constant heat flux of $300 \mathrm{~kW} / \mathrm{m}^{2}$. It is evident that heat transfer coefficients decrease more rapidly as the $\mathrm{CaSO}_{4}$ concentration was increased. This is attributed to the increased supersaturation of the salt solution at the triple interface of vapour, liquid and heat transfer surface. The measurements also confirmed the observations of Najibi et al. (1996), i.e. that an increase in $\mathrm{CaSO}_{4}$ concentration results in bigger bubbles. As it was observed for flow boiling at low heat fluxes, the gap between minimum and maximum heat transfer coefficients decreases as the concentration is reduced.

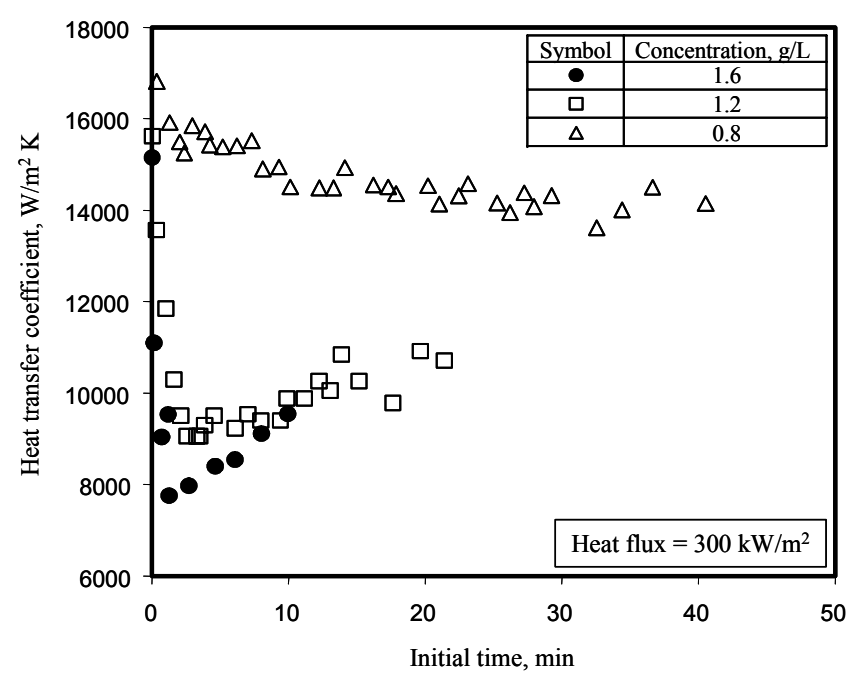

Figure 4. Heat transfer coefficient as a function of time for a given heat flux and different concentrations.

Fig. 5 shows the variation of time to reach minimum and maximum heat transfer coefficients as a function of heat flux, for a constant $\mathrm{CaSO}_{4}$ concentration of $1.6 \mathrm{~g} / \mathrm{L}$. In this figure, minimum and maximum points represent the ends of regions $\mathrm{I}$ and II in Fig. 1, respectively. Two distinctive trends are clearly conspicuous. Firstly, both minimum and maximum values decrease continuously as the heat flux increases. Secondly, the gap between these two times expands with decreasing heat flux.

Experimental data for the time over which the heat transfer coefficient reaches its minimum value are illustrated in Fig. 6 for different salt concentrations. For both concentrations, similar trends as those in Fig. 5 indicate that as concentration decreases, the time to reach 
the minimum heat transfer coefficient increases for all heat fluxes.

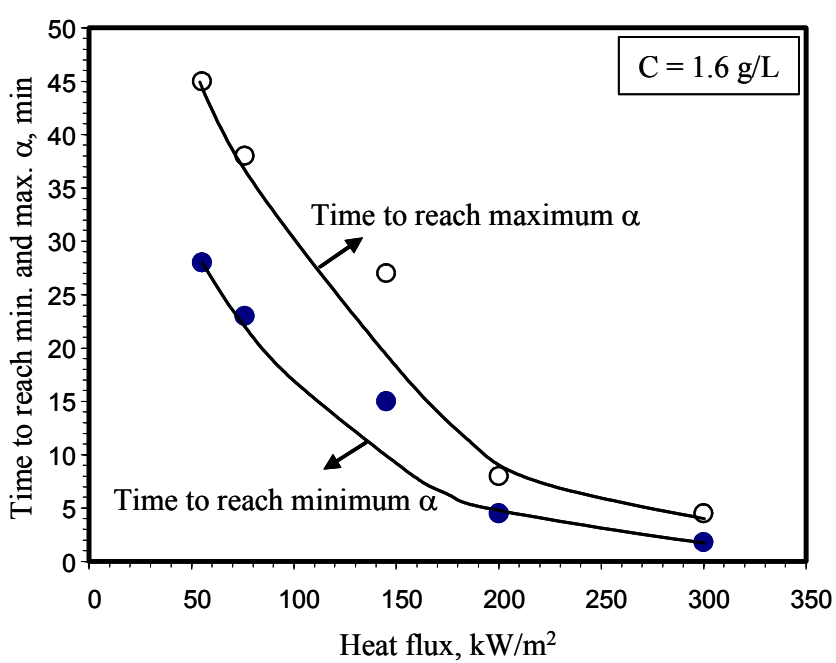

Figure 5. Time to reach minimum and maximum heat transfer coefficients as a function of heat flux for constant $\mathrm{CaSO}_{4}$ concentration.

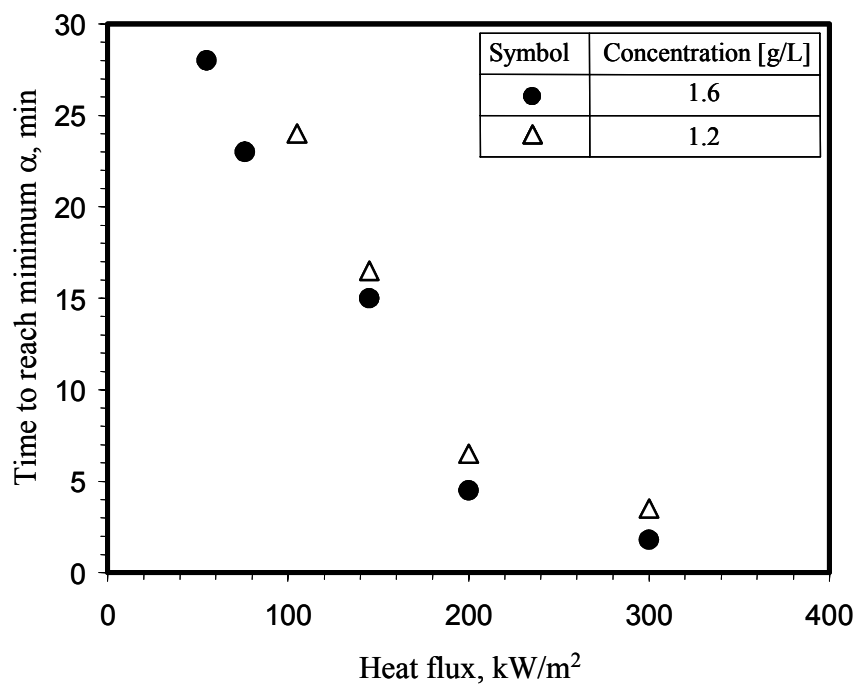

Figure 6. Time to reach minimum heat transfer coefficient as a function of heat flux, for different $\mathrm{CaSO}_{4}$ concentrations.

\section{CORRELATION OF DATA}

Phenomenological correlations for the prediction of fouling behaviour under pool boiling heat transfer are rare and a review of existing models was given by Jamialahmadi and Müller-Steinhagen (1993). They compared their experimental results with previous models but the predictive accuracy was clearly not satisfactory. Moreover, the prediction of the fouling behaviour was limited to region III in Fig. 1, while regions I and II (initial period) have not been investigated and correlated. Not surprisingly, the main reason for this was attributed to the complexity of the fouling behaviour during the initial period. Most recently, Jamialahmadi and Müller-Steinhagen (2004) published a new phenomenological model for the prediction of fouling resistance of calcium sulphate solutions during boiling heat transfer for region III in Fig. 1. In this model, the heat transfer coefficient is expressed as:

$\alpha_{I I I}=\frac{\alpha_{0}}{1+\phi\left(\eta C_{s}^{b}-C^{s a t}\right)^{2}\left(1-e^{-k_{d}\left(t-t_{0}\right)}\right)}$

where $\alpha_{0}$ is the "clean" heat transfer coefficient that could be predicted by Gorenflo's correlation (2001). Also, in this equation:

$\phi=\frac{1}{90.2+5.7 \times 10^{-7} \dot{q}}$

$\eta=\exp \left(2.685 \times 10^{-6} \dot{q}\right)$

$k_{d}=1.1 \times 10^{3} e^{-33650 / R_{g} T_{s}}$

$t_{0}=0.731 \times 10^{-17} / C_{b} e^{-124287 / R_{g} T_{s}}$

$C_{s}^{b}, \mathrm{C}^{\mathrm{sat}}$ and $\mathrm{t}$ are bulk and saturation concentrations, and operating time, respectively. Eq. (5d) provides an estimate of the initial time until the beginning of region III. Jamialahmadi and Müller-Steinhagen (2004) reported that Eq. (4) could predict their experimental results with an error of about $6.5 \%$. However Eq. (4), as stated before, is only limited to region III, and one should endeavour to correlate data within the initial period, as well.

Recent advances in function approximation methods have helped researchers to better analyse and predict objective functions for highly complex processes such as fouling (Malayeri et al. 2001, 2003). One such technique is the artificial neural network architecture which may be utilised for analysing processes in which interaction between independent and dependent variables is poorly understood. The present authors have used neural networks for the prediction of fouling behaviour under subcooled flow boiling conditions and also for $\mathrm{CaSO}_{4}$ precipitation in cooling towers (Malayeri and Müller-Steinhagen, 2001 \& 2003). In addition, they utilised the same techniques for the prediction of void fraction data in two-phase flows (Malayeri et al., 2003). In this study, the artificial neural network architecture is utilised again due to its:

1) ability to interpolate within the range of introduced experimental results. Malayeri et al (2003) used the same technique for extrapolation. However this is 
not possible in this study due to limited number of experimental results that are just enough for the training phase.

2) capability, as will be discussed later, to adopt process prior knowledge as a tool to make sure that the resultant network complies with process constraints. This could be considered as an advantage for possible intelligent heat exchanger monitoring which cannot be possible by conventional regression models (Thompson and Kramer, 1994).

The construction of a neural network in its most basic form involves three entirely different layers. The input layer is made of input nodes. The layer between the input and output layers is known as hidden layer, which may consist of only one or of several sub-layers. In some neural networks such as Radial Basis Functions (RBF), only one hidden layer exists, where in contrast to the multi-layer perceptron, the transformation from input space to the hidden layer space is non-linear, while the transformation from the hidden layer space to the output space is linear. The output layer supplies the response of the network to the activation patterns applied to the input layer. A detailed introduction into the foundations of the radial basis function (RBF) is given by Haykin (1999).

In the present study, for correlating the data, the radial basis function neural network architecture is investigated. Three input dimensionless groups $\left(\dot{q} / \dot{q}_{a r b}, \mathrm{C}_{\mathrm{b}} / \mathrm{C}^{\text {sat }}, \mathrm{t} / \mathrm{t}_{0}\right)$ are defined as vector $\mathbf{x}$ and one output (heat transfer coefficient) as vector $\mathbf{y} . \dot{q}_{a r b}$ is an arbitrary value of heat flux in order to make the input which is related to heat flux dimensionless and hence here is taken as the maximum investigated heat flux, which was $300 \mathrm{~kW} / \mathrm{m}^{2}$.

The network consists of three layers, which are input layer, hidden layer and output layer. The number of nodes of the input layer is equal to the dimension of the input vector $\mathbf{x}$, and here is equal to three. The hidden layer is composed of non-linear units that are connected directly to all of the nodes in the input layer. There is one hidden unit for each data point $\mathbf{x}_{\mathbf{i}}=\mathbf{1}$ to $\mathbf{N}$, where $\mathbf{N}$ is the number of experimental data. The output layer consists of a single linear unit and its output is the heat transfer coefficient. In order to protect the network from under- or over-fitting the following constraints are applied:

$\begin{array}{ll}\text { a } \mathrm{t}=0 & \alpha=\alpha_{0} \\ \text { @ } \mathrm{t} \geq \mathrm{t}_{0} & \alpha=\alpha_{\text {III }}\end{array}$

Here, $\alpha_{0}$ and $\alpha_{\text {III }}$ are determined by the Gorenflo correlation (2001) in conjunction with the model proposed by Jamialahmadi and Müller-Steinhagen (2004). In addition to these constraints, further process information is available to improve the outcome of the resulting network, such as that shown in Figs. 5 and 6:

$$
\begin{aligned}
& \left.\frac{\partial t}{\partial \dot{q}}\right|_{\alpha_{\min }}<0 \\
& \left.\frac{\partial t}{\partial \dot{q}}\right|_{\alpha_{\max }}<0
\end{aligned}
$$

All these constraints will be introduced into the network as "Prior Knowledge (PK)", and the network output should primarily comply with these constraints in order to obtain the correct qualitative results. The available experimental data are usually divided into two sets, for the training and generalisation phases respectively. In the present case, however, all experimental results were used for training because only few data sets have been available the initial deposition period. All input data have been normalised before introducing them to the network. The resulting network was validated by comparison of the network output with those experimental results which have been used in the training phase. The principle of the modelling can be described in more detail with the help of the flow chart in Fig. 7.

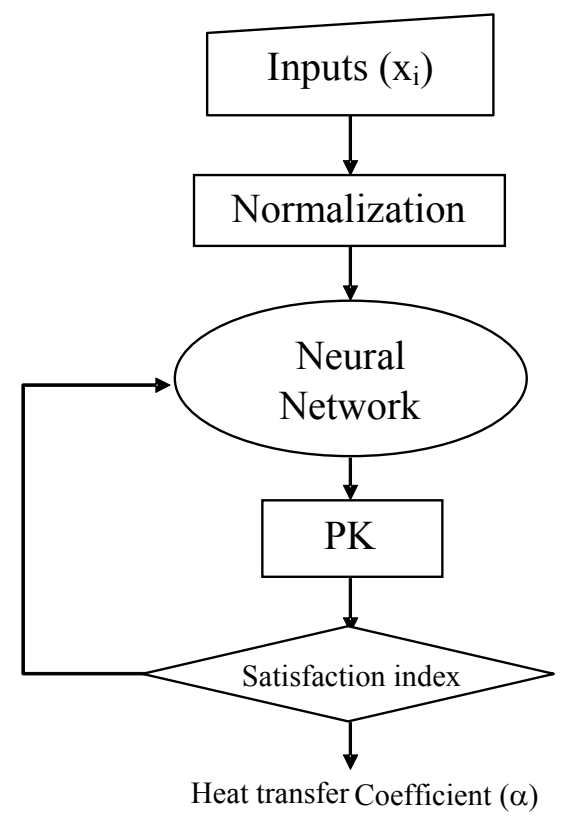

Figure 7. Explanation of the neural network modelling in stepwise layout. 
Fig. 8 illustrates a comparison of the network output against the experimental data shown in Fig. 3. The absolute mean average error is $8.7 \%$ for regions I and II and the maximum error of $23.4 \%$. Even though the accuracy of the established network is good, one can see slightly under- and overprediction after the minimum heat transfer coefficient. The initial under-estimation is partly related to errors in the prediction of the clean heat transfer coefficient by the Gorenflo correlation (2001). It is also noticeable that the accuracy of the resulting network increases for higher heat fluxes, notably for $200 \mathrm{~kW} / \mathrm{m}^{2}$ and above.

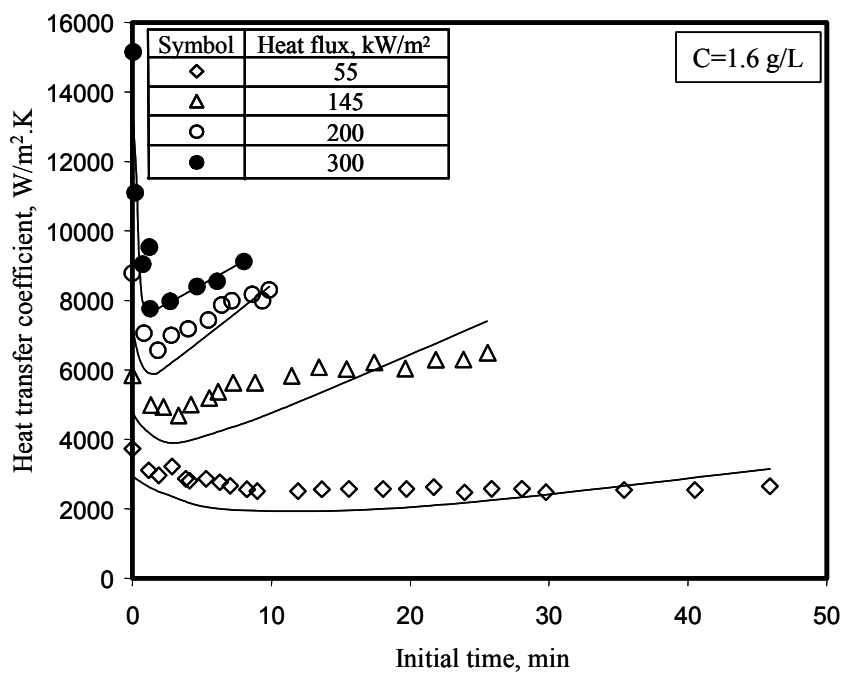

Figure 8. Comparison of network output with experimental data.

It should also be pointed out that noisy data have not been removed from the data sets and that the effect of other parameters that may improve the performance of the network, such as surface finish in terms of surface roughness, were not considered. Surface roughness could not be considered as an input because it was assumed to be constant for all experimental runs. However, for investigations with different surface finishes, this parameter will definitely have to be included as an input vector. Obviously, the quality of the network will improve if more reliable information is available.

\section{CONCLUSIONS}

The principle conclusions that can be made by considering the results of this investigation are:

- The rather short initial period in which significant changes in heat transfer coefficient occurs is decisive for investigation of novel fouling mitigation techniques such as surface modification (Müller-Steinhagen and Zhao, 1997). It is the time in which the first crystalline nuclei become active on the heat transfer surface, whereas in the decay period secondary nuclei are in contact with the deposit layer.

- The time until the heat transfer coefficient reaches its intermediate minimum and maximum values decreases with increasing heat flux and salt concentration, but more dominantly for higher heat fluxes. For any given concentration, the time span between reaching the minimum and maximum heat transfer coefficients widens as heat flux decreases.

- The use of artificial neural networks has helped to correlate the experimental results with good accuracy, even though more reliable data would further improve the capability of the network.

- As a point of precaution, the authors would like to emphasize that the present results are only indicative and that further investigations are required, particularly with respect to the influence of surface finish.

\section{NOMENCLATURE}

$\begin{array}{ll}\mathrm{C} & \text { concentration, } \mathrm{g} \mathrm{L}^{-1} \\ \mathrm{k}_{\mathrm{d}} & \text { deactivation rate constant, } \mathrm{s}^{-1} \\ \dot{\mathrm{q}} & \text { heat flux, } \mathrm{W} \mathrm{m} \mathrm{m}^{-2} \\ \mathrm{R} & \text { cavity radius, } \mathrm{m} \\ \mathrm{R}_{\mathrm{g}} & \text { universal gas constant, } \mathrm{Jmol}^{-1} \mathrm{~K}^{-1} \\ \mathrm{R}_{\mathrm{f}} & \text { fouling resistance, } \mathrm{m}^{2} \mathrm{~K} \mathrm{~W}^{-1} \\ \mathrm{~T} & \text { temperature, } \mathrm{K} \\ \mathrm{t} & \text { time, } \mathrm{s} \\ \mathrm{t}_{0} & \text { transition time until the beginning of region } \\ & \text { III, } \mathrm{s}\end{array}$

\section{Greek Letters}

$\alpha \quad$ heat transfer coefficient, $\mathrm{Wm}^{-2} \mathrm{~K}^{-1}$

$\Delta \mathrm{h}_{\mathrm{v}} \quad$ latent heat of evaporation, $\mathrm{J} / \mathrm{kg}$

$\Delta \mathrm{T}_{\text {superheat }} \quad$ degree of wall superheat $=\mathrm{T}_{\mathrm{s}}-\mathrm{T}_{\text {sat }}, \mathrm{K}$

$\phi \quad$ defined by Eq. (5a)

$\eta \quad$ defined by Eq. (5b)

$\rho_{\mathrm{g}} \quad$ vapour density inside bubble nucleus, $\mathrm{kg} \mathrm{m}^{-3}$

$\sigma \quad$ surface tension, $\mathrm{N} \mathrm{m}^{-1}$

\section{Subscripts and Superscripts}

0 zero time or clean conditions

b bulk

s surface

sat saturation

\section{ACKNOWLEDGMENTS}

The authors are grateful to $\mathrm{Mr}$ T.H. Bartlett whose experimental data were used in this study. 


\section{REFERENCES}

Bartlett, T.H., 1995, Fouling of boiler tubes, MSc thesis, University of Auckland, New Zealand

Bornhorst, A., Zhao, Q. and Müller-Steinhagen, H., 1999, Reduction of Scale Formation by Ion Implantation and Magnetron Sputtering on Heat Transfer Surfaces. Heat Transfer Eng., 20 (2), 6-14.

Freeborn, J. and Lewis, D., 1962, Initiation of boiler scale formation. J. Mech. Sci., 4, 46-52.

Gorenflo, D., 2001, State of art in pool boiling heat transfer of new refrigerants, Int. J. Refrig., 24, 6-14.

Haykin, S.S., 1999, Neural networks: a comprehensive foundation, $2^{\text {nd }}$ edition, Prentice Hall, London, UK.

Hospeti, N.B. and Mesler, R.B., 1965, Deposits formed beneath bubbles during nucleate boiling of radioactive calcium sulphate solutions. AIChE J, 11, 662-665.

Jamialahmadi, M., Blöchl, R., and Müller-Steinhagen, H., 1989, Bubble dynamics and scale formation during nucleate boiling of aqueous calcium sulphate solutions. Chem. Eng. Process., 26, 15-26.

Jamialahmadi, M. and Müller-Steinhagen, H., 1993, Scale formation during nucleate boiling - A review. Corrosion Reviews, 11 (1\&2), 25-54.

Jamialahmadi, M. and Müller-Steinhagen, H., 2004, A new model for the effect of calcium sulfate scale formation on pool boiling heat transfer. ASME J. Heat Transfer, 126, 507-517.

Malayeri, M.R., and Müller-Steinhagen, H., 2001, Neural network analysis of heat transfer fouling data, The $4^{\text {th }}$ United Engineering Foundation Conference on Heat Exchanger Fouling: Fundamental Approaches \& Technical Solutions, Davos, Switzerland, pp. 145-150.
Malayeri, M.R., H. Müller-Steinhagen, and J.M. Smith, 2003, Neural network analysis of void fraction in air/water two-phase flows at elevated temperatures, Chem. Eng. \& Processing, Vol. 42, No. 8/9, pp. 587-597.

Malayeri, M.R., Müller-Steinhagen, H. and Bartlett, T.H., 2005, Fouling of tube bundles under pool boiling conditions, Chem. Eng. Sci., Vol. 60, No.6, pp. 1503-1513.

Müller-Steinhagen, H. and Zhao, Q., 1997, Investigation of low fouling surface alloys made by ion implantation technology. Chem. Eng. Sci., 52, 3321-3332.

Najibi, S.H., Müller-Steinhagen, H. and Jamialahmadi, M., 1996, Boiling and non-boiling heat transfer to electrolyte solutions. Heat Transfer Eng., 17 (4), 46-63.

Palen, J.W. and Westwater, J.W., 1966, Heat transfer and fouling rates during pool boiling of calcium sulphate solutions. Chem. Eng. Prog. Symp. Series, 62(64), 77-86.

Partridge, E.P. and White, A.H., 1929, Mechanism of formation of calcium sulphate boiler scale. Ind. Eng. Chem., $21,834-838$.

Thompson M.I. and Kramer, M.A., 1994, Modelling chemical processes using prior knowledge and neural network, AIChE J., Vol. 40, pp. 1328-1340.

Whalley, P.B., 1996, Two-phase flow and heat transfer. Oxford University Press, NY, USA. 